\title{
Development of two socioeconomic indices for Saudi Arabia
}

\author{
Reem S. AlOmar ${ }^{1 *}$ (D), Roger C. Parslow ${ }^{2}$ and Graham R. Law ${ }^{3}$
}

\begin{abstract}
Background: Health and socioeconomic status (SES) are linked in studies worldwide. Measures of SES exist for many countries, however not for Saudi Arabia (SA). We describe two indices of area-based SES for SA.

Methods: Routine census data has been used to construct two indices of SES at the geographically-delimited administrative region of Governorates in SA $(n=118)$. The data used included indicators of educational status, employment status, car and material ownership. A continuous measure of SES was constructed using exploratory factor analysis (EFA) and a categorical measure of SES using latent class analysis (LCA). Both indices were mapped by Governorates.
\end{abstract}

Results: The EFA identified three factors: The first explained $51.58 \%$ of the common variance within the interrelated factors, the second $15.14 \%$, and the third $14.26 \%$. These proportions were used in the formulation of the standard index. The scores were fixed to range from 100 for the affluent Governorate and 0 for the deprived. The LCA found a 4 class model as the best model fit. Class 1 was termed "affluent" and included 11.01\% of Governorates, class 2 "upper middle class" (44.91\%), class 3 "lower middle class" (33.05\%) and class 4 "deprived" (11.01\%). The populated urbanised Governorates were found to be the most affluent whereas the smaller rural Governorates were the most deprived.

Conclusion: This is the first description of measures of SES in SA at a geographical level. Two measures have been successfully constructed and mapped. The maps show similar patterns suggesting validity. Both indices support the common perception of SES in SA.

Keywords: Saudi Arabia, Socioeconomic status, Exploratory factor analysis, Latent class analysis, Deprivation

\section{Background}

Inequality in health outcomes, and access to health services and their utilisation due to socioeconomic status (SES) is a common theme in health research and policy intervention [1]. It is acknowledged that SES affects both morbidity and mortality, and has been linked to low birth weight, cardiovascular diseases, arthritis, hypertension, diabetes and cancer [2, 3].

The trend in health research has shifted from the sole use of individual-based socioeconomic data to an approach that includes area-based aggregate data, this approach is more convenient as one composite index can be easily included into public health surveillance programs, as opposed to adding several individual data

\footnotetext{
* Correspondence: rsomar@iau.edu.sa

1 Department of Family and Community Medicine, Imam Abdulrahman Bin

Faisal University, Dammam, Saudi Arabia

Full list of author information is available at the end of the article
}

items [4]. This analysis typically includes matching individuals' residential information such as postcodes to a spatial location, thus creating area-profiles that are easy to use in research [5].

Focus on health disparities attributable to SES allows governments and health organisations to target interventions, especially in deprived populations $[6,7]$. In the UK for example, the measurement of SES has a long history, where indices such as Townsend [8], Carstairs [9] and the IMD [10] have been developed and are continuously updated for health research and policy intervention purposes. Other countries have also developed their own area-based indices of SES, in Europe [11], the US [12], Canada [13] and others [14, 15].

Measurements of SES in the Gulf countries and in Saudi Arabia (SA) specifically, are not well developed. The standard measure of SES used in health research in

(c) The Author(s). 2018 Open Access This article is distributed under the terms of the Creative Commons Attribution 4.0 International License (http://creativecommons.org/licenses/by/4.0/), which permits unrestricted use, distribution, and reproduction in any medium, provided you give appropriate credit to the original author(s) and the source, provide a link to the Creative Commons license, and indicate if changes were made. The Creative Commons Public Domain Dedication waiver (http://creativecommons.org/publicdomain/zero/1.0/) applies to the data made available in this article, unless otherwise stated. 
these countries rely solely on individual characteristics such as income, and educational status and these measures fail to account for the social and health context $[16,17]$. To our knowledge, no study has yet examined the relationship between any health outcome and SES on an area-based level in the Gulf region, because no area-based measure exists for any of these countries. In $\mathrm{SA}$, the problem persists, but is worsened by the fact that SA is the largest country in the Gulf [18]. Unlike the UK and other industrialised countries, it is a common perception that rural areas in SA are the most deprived in terms of education, income and health outcomes, where travelling distances to higher educational institutions and specialised health organisations are larger for those living within the more rural areas.

Therefore, the present study aims to formulate two socioeconomic indices for SA at the Governorate level, and provide geographical representations of them. These indices will explore and possibly validate the common perception of SES in SA.

\section{Methods}

\section{Population data}

The national census data of 2004 from the General Authority for Statistics in SA was used for this analysis [19]. There are two main geographical levels for the country, the 13 provinces, and nested within these are 118 Governorates. Each province has a different number of Governorates. The average population within the Governorates is 192,189 , and the median is 57,792 . The population ranges from 4,138,329 in the capital Riyadh to 3785 in Kharkheer. The geographical level of analysis in this study is the Governorate level, since that is the geographical level at which most administrative and health data are collected, and also for data accessibility issues.

\section{Indicator variables}

The national census of SA does not collect information on a specific measure of social class explicitly, and household income and overcrowding data was not disclosed by those surveyed [19]. The accessible indicators (available in aggregated form at: https://www.stats.gov.sa/en) used are summarised in Table 1.

\section{Digital boundary data}

Digital boundaries of the 118 Governorates of the country facilitated geo-referenced data linkage and were provided from Farsi GeoTech Company [20].

\section{Statistical analysis}

Two indices of SES will be developed using two different statistical methodologies. The motive is to come up with two types of indices, one continuous with detailed information on each Governorate (Standardised index of SES), and the other categorical where several similar Governorates are combined into one category or class (Socioeconomic classes).

\section{Standardised index of SES}

An exploratory factor analysis (EFA) was used to estimate the underlying latent structure of the indicators. The assumption underlying EFA is that the correlations between the indicators are from the common factors [21].

First, all indicators were expressed as proportions using indicator specific denominators where required since the denominators varied in some indicators. The validity of an EFA was tested using Bartlett's test and Kaiser-Meyer-Olkin (KMO) test. The former tests whether the correlation matrix is an identity matrix and the latter tests whether the partial correlation coefficients are small $[22,23]$. The KMO and Bartlett's tests show that the data is appropriate for an EFA, KMO = 0.72 , and $P$-value $<0.01$ respectively. Three factors were retained, accounting for $51.58,15.14$ and $14.26 \%$ of the variance respectively. The factor scores were obtained as a linear combination of the standardised indicators.

The principle factor method was used to extract the factors from a correlation matrix of which the diagonal component are estimated communalities instead of having a value of 1 [24]. The decision on the number of factors to retain was based on the Kaiser Rule and interpretability. The eigenvalue is the amount of common variance that is explained by each factor. Since the indicators are not assumed to be mutually exclusive to one factor, an oblique rotation was used to allow the resulting factors to correlate. This method allows the factor axes identified from the initial extraction to rotate to give a simple structure and hence the factors have become more interpretable [21]. Also, as each Governorate has a proportion of every indicator, therefore a variable loading on two factors is acceptable.

The resulting three factors have been used to calculate a standardised index (SI) of SES. An initial index had to be calculated first, which takes into account the eigenvalue of each factor as weights of each extracted factor in explaining the total variance:

$$
I I=\left[\left(F_{1}\right)\left(W_{1}\right)\right]+\left[\left(F_{2}\right)\left(W_{2}\right)\right]+\left[\left(F_{3}\right)\left(W_{3}\right)\right]
$$

where $F_{1}$ is the score of factor 1 and $W_{1}$ is the weight of factor 1 . The values from this index give both positive and negative values, making it difficult to interpret the results. As an example, therefore, a SI based on the initial index has been calculated for the Abha Governorate as: 


$$
S I_{a b h a}=\frac{I I_{a b h a}-\operatorname{Min}_{I I}}{\operatorname{Max}_{I I}-\operatorname{Min}_{I I}}
$$

The SI index measures the SES of one Governorate relative to the difference between the most affluent (Max initial index) and least affluent Governorates (Min initial index). The results range from 100 to 0 , where 100 is the score of the most affluent Governorate and 0 is the score of the most deprived Governorate. The analysis was performed in Stata software version 12 [25].

\section{Socioeconomic classes}

The latent class analysis (LCA) approach was used to produce a categorical index of SES. The analysis fits a model that identifies a subset of latent classes to the data and then generates probabilities for each Governorate to belong to each class. Then Governorates are classified into classes by modal assignment, in which they belong to the class with the highest probability [26].

The maximum likelihood method was used to estimate the LCA model parameters. To avoid the problem of sample size related non-convergence (local maxima), the indicator variables used were limited to 11 which represent socioeconomic disadvantages which are "Not in the labour force", "Illiterate", "No car", "Living in traditional housing", "Living in one floor in a traditional house", "House not owned", "No phone", "No television", "No internet", "No library" and "No satellite" (Table 1). This is to allow for the rule of thumb which states that a minimum of 10 observations are needed for each

Table 1 Indicators used in the measurement of socioeconomic status for Saudi Arabia

\begin{tabular}{|c|c|c|}
\hline Categories & Indicator variables & Denominator \\
\hline \multirow[t]{4}{*}{ Educational status } & Illiterate and read/write & Population aged $>10$ years \\
\hline & School degree & \\
\hline & Diploma and university & \\
\hline & Higher education & \\
\hline \multirow[t]{5}{*}{ Employment status $^{\mathrm{a}}$} & In the labour force & Population aged $>15$ years \\
\hline & Students & \\
\hline & Housewives & \\
\hline & Retired & \\
\hline & Other employment & \\
\hline \multirow[t]{5}{*}{ Type of housing } & Traditional house & Households \\
\hline & Villa & \\
\hline & A floor in a traditional house or villa & \\
\hline & Apartment & \\
\hline & Other type of housing & \\
\hline \multirow[t]{4}{*}{ Tenure of housing ${ }^{b}$} & Owned & Households \\
\hline & Rented & \\
\hline & Provided & \\
\hline & Other tenure & \\
\hline \multirow[t]{3}{*}{ Car ownership } & No car & Households \\
\hline & One car & \\
\hline & Two or more cars & \\
\hline \multirow[t]{8}{*}{ Material ownership } & Phone available/not available & Households \\
\hline & TV available/not available & \\
\hline & PC available/not available & \\
\hline & Internet available/not available & \\
\hline & Library available/not available & \\
\hline & Satellite available/not available & \\
\hline & Videos available/not available & \\
\hline & Video games available/not available & \\
\hline
\end{tabular}

"In the latent class analysis employment status the following indicators: "Students", "Housewives" and "Retired" were combined to "Not in the labour force"

bIn the latent class analysis tenure of housing indicators the following indicators: "Rented", "Provided" and "Other tenure" were combined into "House not owned" 
indicator variable [27]. Furthermore, to ensure a global maximum solution, the number of random starting values were increased to 1000 , and 100 optimizations were used [28].

The process started by estimating a one class model and increasing the number of classes gradually to a $\mathrm{k}$-class model (27). The model fit indices examined have included the Akaike Information Criterion (AIC), Bayes Information Criterion (BIC), the sample size-adjusted BIC, the Lo-Mendel-Rubin likelihood ratio test (LMR-LRT), the bootstrapped likelihood ratio difference test (BLRT) and the entropy (27). The lower the values of the AIC, BIC and the sample-size adjusted BIC, the better the model fit. A nonsignificant $p$-value $(P<0.05)$ of LMR-LRT and BLRT indicates that the $\mathrm{k}-1$ model is the most parsimonious model. An entropy value close to one indicates a good classification (27). In any case, BIC and the BLRT statistics are recommended and are superior to other test statistics as evidenced by a recent simulation study [29].

In our data, the entropy is 0.98 for a 2 -class and a 4-class solution as well as the $P$-value being significant $(<0.01)$ for both. However, a 4-class solution attained the lowest value of AIC, BIC, adjusted BIC, and BLRT, as well as yielding a classification that was clearly distinct and interpretable, and this was chosen for the LCA (Table 2). Analysis was performed in Mplus version 7 [28].

\section{Results}

The descriptive statistics on all indicator variables are given in Table 3. The "other tenure" category shows a slight skewness (3.33), as it includes homes that are given by charity or temporarily by a relative and these are very rare cases. The "higher education", "other type of housing" and "other tenure" variables all have a very high kurtosis (12.46, 15.51 and 15.91 respectively). This indicates that the number of people with higher education, people who live in other types of homes and on

Table 2 Fit statistics for latent class analysis incorporating 11 indicator variables

\begin{tabular}{llllll}
\hline & 1 class & 2 classes & 3 classes & 4 classes & 5 classes $^{a}$ \\
\hline Parameters & 22 & 34 & 46 & 58 & 70 \\
H0 value & 977.32 & 1318.219 & 1415.645 & 1567.115 & - \\
AIC & -1910.64 & -2568.44 & -2739.29 & -3018.23 & - \\
BIC & -1849.69 & -2474.23 & -2611.84 & -2857.53 & - \\
Adj BIC & -1919.23 & -2581.72 & -2757.26 & -3040.88 & - \\
Entropy & $\mathrm{n} / \mathrm{a}$ & 0.984 & 0.95 & 0.984 & - \\
VLMR & $\mathrm{n} / \mathrm{a}$ & 0.0004 & 0.4163 & 0.0281 & - \\
BLRT & $\mathrm{n} / \mathrm{a}$ & 0 & 0 & 0 & -
\end{tabular}

${ }^{a}$ The number of free parameters is too high to come up with trustworthy standard errors other type of tenures is small, where the maximum values of these variables are $0.01,0.54$, and 0.07 respectively.

\section{Standardised index of SES}

Table 4 shows the loadings of the three factors. The "Students" indicator variable was found to be highly loading on Factors 2 and 3 (0.65 and 0.62 respectively). Factor 1 described the Governorates with a large proportion of the population that are mostly educated, in the labour force, live in rented apartments, own a car and have all important household items. Factor 2 described Governorates with a large proportion of the population who live in villas and own two or more cars. Factor 3 described Governorates with a large proportion of the population who are not in the labour force, live in traditional houses that are owned not rented.

The proportions of the eigenvalues of the three factors have been used in calculating the initial index from eq. 1, which resulted in Governorates ranging from 37.83 for the most affluent Governorate, Qatif, to -43.09 for the most deprived Governorate, Kharkheer. These were then standardised to range from 100 to 0 (Additional file 1).

\section{Socioeconomic classes}

The model fit statistics for a 1 to 5 -class solution are presented in Table 2. Class 1 has 13 Governorates (11.01\%) and is labelled the "affluent class", class 2 has 53 Governorates (44.91\%) and is labelled the "upper middle class", class 3 has 39 Governorates (33.05\%) and is labelled the "lower middle class" and class 4 has 13 Governorates (11.01\%) and is labelled "the deprived class" (Additional file 2).

Figures 1 and 2 illustrate how the Governorates are distributed geographically according to the standardised index and the SES class index.

The Figs. 1 and 2 show that the metropolitan Governorates of Riyadh, Jeddah and Dammam are affluent, as was expected. In the standardised index, the Kharkheer Governorate is the most deprived. Kharkheer is a very rural small Governorate and it is over 300 miles away from the closest area, Sharourah. One of the minor differences between the two indices is that Kharkheer is assigned to the "lower middle class" in the SES class index.

\section{Discussion}

This is the first study that has attempted to develop area-based measures of SES in SA using routinely collected census data. Two replicable indices of SES have been successfully formulated using multiple socioeconomic indicators available from the 2004 national census data at the Governorate level. Previous studies of health 
Table 3 Major categories and sub-categories of socioeconomic indictors and their descriptive statistics

\begin{tabular}{|c|c|c|c|c|c|c|}
\hline Variables $^{a}$ & Mean & SD & Skewness & Kurtosis & Min & Max \\
\hline \multicolumn{7}{|l|}{ Educational status } \\
\hline Illiterate \& read/write & 00.40 & 00.09 & 00.43 & 03.74 & 00.18 & 00.73 \\
\hline School degree & .49 & 00.06 & -00.56 & 04.68 & 00.22 & 00.66 \\
\hline Diploma \& university & .09 & 00.03 & 00.35 & 03.69 & 00.01 & 00.20 \\
\hline Higher education & 0 & 0 & 02.55 & 12.46 & 0 & 00.01 \\
\hline \multicolumn{7}{|l|}{ Employment status } \\
\hline In the labour force & .48 & 00.07 & 00.32 & 02.64 & 00.31 & 00.66 \\
\hline Students & .17 & 00.03 & -00.54 & 03.94 & 00.05 & 00.23 \\
\hline Housewives & 00.26 & 00.05 & 00.51 & 03.22 & 00.16 & 00.41 \\
\hline Retired & 00.03 & 00.01 & 00.11 & 02.62 & 0 & 00.06 \\
\hline Other employment & 00.03 & 00.01 & 00.86 & 03.37 & 0 & 00.08 \\
\hline \multicolumn{7}{|l|}{ Type of housing } \\
\hline Traditional house $(\mathrm{TH})$ & 00.44 & 00.22 & 00.39 & 01.96 & 00.03 & 00.89 \\
\hline Villa & 00.20 & 00.13 & 00.20 & 01.70 & 00.01 & 00.51 \\
\hline Floor in TH or villa & 00.07 & 00.05 & 00.78 & 02.74 & 0 & 00.23 \\
\hline Apartment & 00.17 & 00.14 & 01.51 & 04.94 & 0 & 00.64 \\
\hline Other type of housing & 00.10 & 00.07 & 02.73 & 15.51 & 00.01 & 00.54 \\
\hline \multicolumn{7}{|l|}{ Tenure of housing } \\
\hline Home owned & 00.57 & 00.14 & -00.32 & 02.37 & 00.24 & 00.84 \\
\hline Home rented & 00.26 & 00.12 & 00.79 & 03.53 & 0 & 00.63 \\
\hline Home provided & 00.15 & 00.09 & 01.41 & 05.57 & 00.02 & 00.51 \\
\hline Other tenure & 00.01 & 00.01 & 03.33 & 15.91 & 0 & 00.07 \\
\hline \multicolumn{7}{|l|}{ Car ownership } \\
\hline No car available & 00.29 & 00.09 & 00.78 & 03.00 & 00.12 & 00.53 \\
\hline One car & 00.46 & 00.07 & 00.35 & 03.29 & 00.27 & 00.69 \\
\hline Two or more cars & 00.24 & 00.08 & -00.33 & 02.07 & 00.03 & 00.38 \\
\hline \multicolumn{7}{|l|}{ Household amenities } \\
\hline Phone not available & 00.46 & 00.19 & 00.66 & 02.66 & 00.13 & 00.96 \\
\hline TV not available & 00.21 & 00.12 & 01.30 & 05.39 & 00.03 & 00.72 \\
\hline PC not available & 00.80 & 00.11 & -00.96 & 03.93 & 00.43 & 00.98 \\
\hline Internet not available & 00.87 & 00.08 & -01.36 & 05.16 & 00.58 & 00.99 \\
\hline Library not available & 00.84 & 00.08 & -00.70 & 03.15 & 00.57 & 00.98 \\
\hline Satellite not available & 00.63 & 00.17 & -00.57 & 03.14 & 00.13 & 00.97 \\
\hline Video not available & 00.78 & 00.13 & -00.85 & -03.25 & 00.35 & 00.98 \\
\hline Video games not available & 00.77 & 00.09 & -00.34 & 02.85 & 00.48 & 00.97 \\
\hline
\end{tabular}

${ }^{a}$ Numbers are proportions, calculated by using indicator specific denominators

in SA have not looked at SES in relation to their outcome of interest, due to the lack of any indices [30, 31].

Although the two indices have been formulated using two very different statistical methods, they have yielded very similar results, which indicates validity. The EFA method focuses on grouping variables, whereas the LCA method focuses on grouping observations. Therefore, small differences are to be expected. Nonetheless, the general pattern of affluency and deprivation of the
Governorates were almost the same, only minor differences were found in the more deprived Governorates.

The two indices have shown that 8 out of 11 Governorates in the Eastern province are within the most affluent Governorates of the country (Qatif, Khobar, Rass Tanourah, Jubail, Dammam, Bqeeq, Ahsa and Khafji). The Eastern province hosts 5 major universities within the country, as well as ARAMCO, one of the world's largest oil companies. The Jubail 
Table 4 Factor loadings from principle component factor analysis after oblique rotation

\begin{tabular}{|c|c|c|c|}
\hline Variable & Factor1 & Factor2 & Factor3 \\
\hline \multicolumn{4}{|l|}{ Educational status } \\
\hline Illiterate \& read/write & -0.90 & & \\
\hline School degree & 0.83 & & \\
\hline Diploma \& university & 0.80 & & \\
\hline Higher education & 0.81 & & \\
\hline \multicolumn{4}{|l|}{ Employment status } \\
\hline In the labour force & 0.64 & & -0.66 \\
\hline Student & & 0.65 & 0.62 \\
\hline Housewives & -0.60 & & 0.38 \\
\hline Retired & -0.60 & & \\
\hline Other employment & -0.63 & & 0.42 \\
\hline \multicolumn{4}{|l|}{ Type of housing } \\
\hline Traditional house (TH) & -0.70 & & 0.30 \\
\hline Villa & & 0.62 & \\
\hline A floor in a TH or villa & 0.41 & 0.41 & \\
\hline Apartment & 0.86 & -0.36 & \\
\hline Other type of housing & -0.38 & & -0.81 \\
\hline \multicolumn{4}{|l|}{ Tenure of housing } \\
\hline Home owned & -0.75 & & 0.43 \\
\hline Home rented & 0.89 & & \\
\hline Home provided & & & -0.81 \\
\hline Other type of tenure & & -0.32 & 0.30 \\
\hline \multicolumn{4}{|l|}{ Car ownership } \\
\hline No car & -0.45 & -0.44 & \\
\hline One car & 0.48 & -0.42 & 0.33 \\
\hline \multicolumn{4}{|l|}{ Household amenities } \\
\hline Two or more cars & & 0.86 & \\
\hline Phone available & 0.80 & & \\
\hline TV available & 0.75 & & \\
\hline PC available & 0.90 & & \\
\hline Internet available & 0.92 & & \\
\hline Library available & 0.90 & & \\
\hline Satellite available & 0.88 & & \\
\hline Video available & 0.86 & & \\
\hline Video games available & 0.91 & & \\
\hline
\end{tabular}

Governorate in the northern part of the Eastern region is the largest industrial city in the Middle East. Therefore, it is understandable to find these Governorates to be within the most affluent, especially that the Eastern province is the gate towards the rest of the gulf countries. The major cities in the country, such as the capital Riyadh and Jeddah were also within the affluent ranking in the SI and affluent ranking from the SES class index.
The selection of indicators was critical. The analysis began with a close examination of what has been chosen to formulate socioeconomic indices in other countries. The Townsend and Carstairs indices in the UK, as well as the indices in the US and Spain have all utilised indicators available from national censuses. Unlike the Saudi census, the censuses used in formulating these indices have included important indicators such as unemployment and overcrowding. Although the Saudi census does have a variable of employment status, this variable only shows the proportion that are in the labour force, and this variable includes the proportion of the population who are available for work, hence it includes both the employed and the unemployed. Furthermore, the Saudi census collects information on the number of rooms per household, therefore the information necessary to create an overcrowding variable are available but have not been accessible. Consequently, a decision was made that balanced between what had to be included and what was available and accessible from the census. Of interest is the student variable, which had a dichotomy on two factors, Factor 2 and Factor 3. A Governorate that has a high proportion of students may indicate that the Governorate is either affluent or poor. This variable covers the population aged $>15$ years. Therefore, it includes both university students and mature students ( $>21$ years old) returning to schools to gain better jobs. Both of which explain why the variable loads highly onto the two factors.

Similar to the Townsend index [8], the final numerical value assigned to each Governorate in the standardised index does not measure a specific object. The value provides an abstract measure of deprivation that is used to rank these Governorates [32]. The standardised index method has been used to develop an index for Canada [33], India [34, 35], Japan [36] and the State of Mississippi in the USA [37]. However, none of these studies have attempted to re-construct the index using another statistical method for extra validity. The LCA approach was chosen to be able to construct a categorical class of SES to be used in future analyses; hence, Saudi researchers have the choice between a continuous and a categorical index.

Naturally, with the standardised index, more detail is given with regards to where a certain Governorate stands compared to the others, in contrast to the socioeconomic class index where Governorates are aggregated into four classes, each sharing similar characteristics amongst them. If we were to compare the results of these indices with those of Townsend and Carstairs - calculated on the census ward level - it can be seen that the rural wards had lower scores demonstrating affluence in these areas whilst the urban areas had higher scores demonstrating deprivation. In contrast, in 


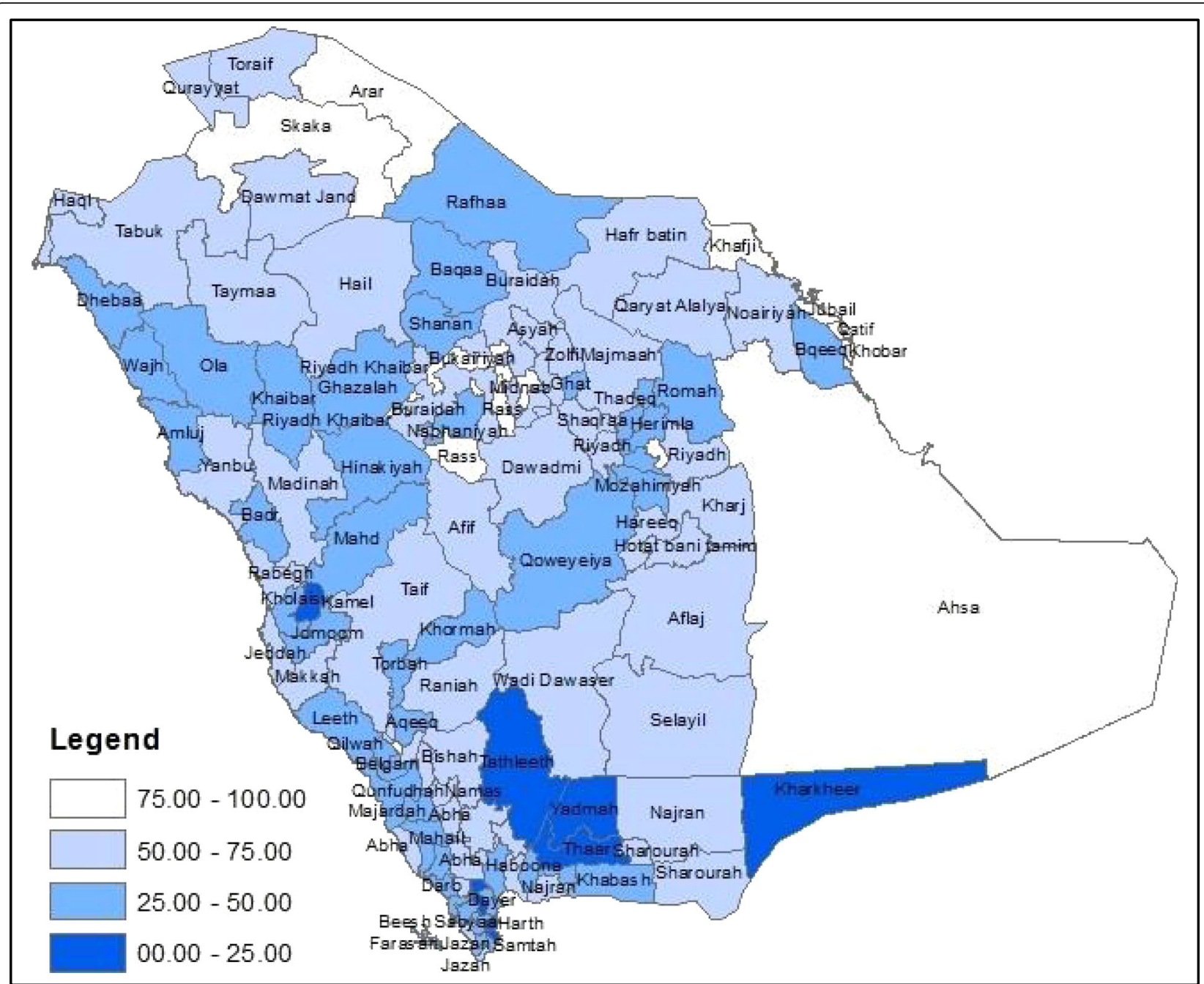

Fig. 1 Map of Saudi Arabia illustrating the boundaries of the Governorates and their ranking from the most affluent to the most deprived as demonstrated by the standardised index of socioeconomic status. *The Empty Quarter desert is included in the border of the Ahsa Governorate, only $18 \%$ of this Governorate is inhabited

Saudi Arabia, rural Governorates had lower scores in the standardised index and were categorised as either being in the 'lower middle class' or the 'most deprived class' in the class index. It is one of the societal characteristics of Saudi Arabia to consolidate in one specific area that has higher educational institutions and specialised healthcare services. Usually these are associated with more job opportunities for the unemployed and have more economical and financial opportunities for those interested in engaging in businesses. Therefore, these areas are generally characterised by affluence.

Although, the two indices have been able to pinpoint the most deprived Governorates, thus aiding in policy making, as well as their validity for use with data collected on a national scale, such as disease registries. They do have a few limitations. First, the indices are on a Governorate level, and Governorates range from large cities such as the capital Riyadh to small villages such as Kharkheer. Misclassification bias is a problem that occurs with categorical variables such as that of the socioeconomic class index, as a result of assigning each Governorate to a class, for example, assigning Riyadh to the affluent class, hence, assuming that all the population of Riyadh are affluent, which is not true.

The use of the 2004 census is arguably outdated and may not reflect the current situation within SA. However, considering that these socioeconomic indices have been developed for the first time, it is worth using the 2004 census which was carried out at a time prior to the social, cultural, economical and educational changes that have been implemented within the country. Such changes have included the establishment of over 26 universities across all provinces in SA, as well as the establishment of The Custodian of The Two Holy Mosques' 


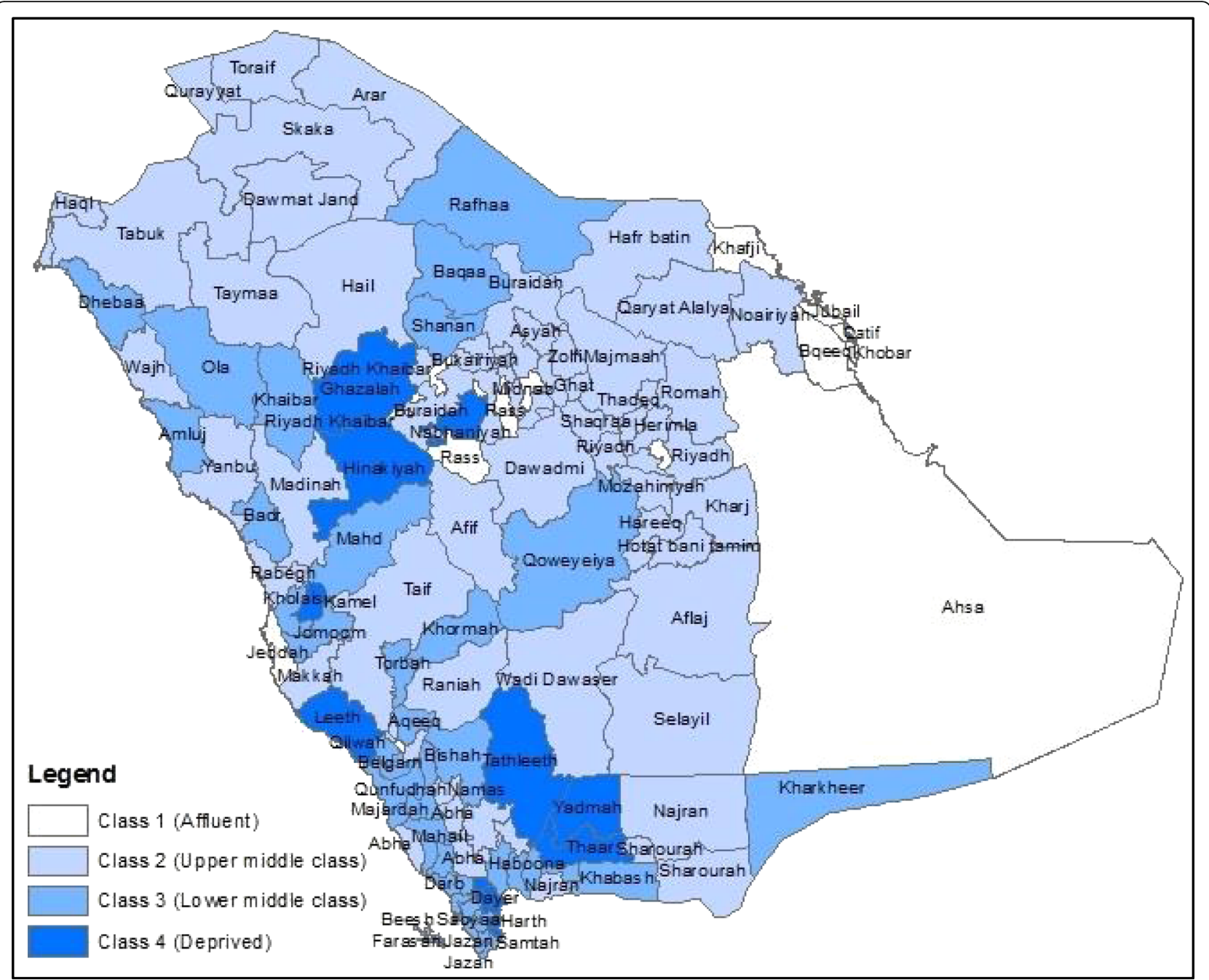

Fig. 2 Map of Saudi Arabia illustrating the boundaries of the Governorates and their socioeconomic classes as demonstrated by the classes of socioeconomic status. *The Empty Quarter desert is included in the border of the Ahsa Governorate, only $18 \%$ of this Governorate is inhabited

Overseas Scholarship Program in 2005 which has supported tens of thousands of Saudis' to study in top ranking universities worldwide in diverse scientific programs [38]. This would allow us to compare and contrast the results of these indices with those that will be developed based on the 2010 census in a rapidly changing country.

The modifiable aerial unit problem is a methodological issue, whereby the choice of this geographical scale is made based on administrative/political convenience rather than being based on sound empirical evidence [39]. One way to overcome these problems is to be able to reproduce these indices on a finer geographical scale. The introduction of the new postal system that has started in 2011 is an excellent new opportunity and has motivated this work. It will facilitate the process of selecting smaller boundaries, for example a residential zip code to be able to assign individuals to spatial locations. Smaller boundaries will ensure that the population within these areas are more homogenous, hence, increasing the reliability of these analyses. Those health organisations wishing to use area-based measures of SES should incorporate these newly developed residential addresses into their databases for data linkage.

\section{Conclusions}

The examination of area-based SES will encourage the study of health inequalities in SA, and provide a valid measure to be used in future researches, as well as provide disease registries in Saudi with the opportunity of including these measures within the patient information to facilitate their use among researchers. In conclusion, two replicable area-based measures of SES have been constructed for the 118 Governorates of SA. The indices have shown very similar results, mainly metropolitan cities are the most affluent groups, and the smaller villages to be within the most deprived. These indices may be 
updated and replicated with the publication of the next national census.

\section{Additional files}

Additional file 1: Title and description of data: Results of the standardised index of socioeconomic status for the 118 Governorates of Saudi Arabia. (DOCX 25 kb)

Additional file 2: Title and description of data: Results of the index of socioeconomic classes for the 118 Governorates of Saudi Arabia. (DOCX $22 \mathrm{~kb})$

\section{Abbreviations}

AIC: Akaika Information Criterion; BIC: Bayes Information Criterion; BLRT: Bootstrapped likelihood ratio difference test; EFA: Exploratory factor analysis; KMO: Kaiser-Meyer-Olkin; LCA: Latent class analysis; LMR-LRT: LoMendel-Rubin likelihood ratio test; SA: Saudi Arabia; SES: Socioeconomic status; SI: Standardised index

\section{Acknowledgments}

We would like to thank the employees at The General Authority for Statistics for their help in accessing the census data, especially Mr. Othaim AlOthaim for his ongoing support throughout the process of data collection and his helpful input in explaining the census data. We would also like to thank the Engineer Zaki Farsi for his generosity in sending us the digital maps of Saudi Arabia.

\section{Funding}

This work was supported by Imam Abdulrahman Bin Faisal University, as part of a scholarship for a PhD from the University of Leeds. Graham Law and Roger Parslow are funded by HEFCE.

\section{Availability of data and materials}

The data that support the findings of this study are available from The General Authority for Statistics in Saudi Arabia available at https:// www.stats.gov.sa/en

\section{Authors' contributions}

RA has analysed, interpreted and written the manuscript. Both RP and GL have supervised the first author throughout her project, contributing towards the conceptual design, analysis, and interpretation and have revised and edited the manuscript. All authors read, provided revisions, and approved the final manuscript.

\section{Ethics approval and consent to participate}

Ethical approval was obtained from The Faculty of Medicine and Health Research Ethics Committee at The University of Leeds.

\section{Consent for publication}

Not-applicable.

\section{Competing interests}

The authors declare that they have no competing interests.

\section{Publisher's Note}

Springer Nature remains neutral with regard to jurisdictional claims in published maps and institutional affiliations.

\section{Author details}

'Department of Family and Community Medicine, Imam Abdulrahman Bin Faisal University, Dammam, Saudi Arabia. ${ }^{2}$ Division of Epidemiology and Biostatistics, University of Leeds, Leeds, UK. ${ }^{3}$ Community and Health Research Unit, School of Health and Social Care, University of Lincoln, Lincoln, UK.
Received: 2 March 2018 Accepted: 18 June 2018

Published online: 26 June 2018

\section{References}

1. Deaton A. Health, inequality, and economic development. J Econ Lit. 2003; 41(1):113-58.

2. NCHS. Health, United States, 2011: With special features on socioeconomic status and health. National Centre for Health Statistics: Hyattsville; 2012.

3. Adler NE, Newman K. Socioeconomic disparities in health: pathways and policies. Health Aff. 2002;21(2):60-76.

4. Kriegar N, Chen J, Waterman P, Soobader M, Subramanian S, Carson R. Choosing area based socioeconomic measures to monitor social inequalities in low birth weight and childhood lead poisoning: the public health disparities geocoding project (US). J Epidemiol Community Health. 2003:57(3):186-99.

5. Denny K, Davidson MJ. Area-based socioeconomic measures as tools for health disparities research, policy and Planning. Can Public Health Assoc. 2012;103(2): S4-S6

6. Marmot M. Global action on social determinants of health. Bull World Health Organ. 2011:89(10)

7. Thomas SB, Quinn SC, Butler J, Fryer CS, Garza MA. Toward a fourth generation of disparities research to achieve health equity. Annu Rev Public Health. 2011;32(1):399-416.

8. Townsend P, Phillimore P, Beattie A. Health and deprivation: inequality and the north: Croom Helm; 1988.

9. Carstairs V Morris R. Deprivation and health in Scotland: Aberdeen University Press; 1991.

10. DCLG. English indices of deprivation 2010. London: Department for Communities and Local Government; 2011.

11. Bajekal M, Jan S, Jarman B. The Swedish UPA score: an administrative tool for identification of underprivileged areas. Scand J Public Health. 1996;24(3): 177-83.

12. Singh GK. Area deprivation and widening inequalities in US mortality, 19691998. Am J Public Health. 2003;93(7):1137-43.

13. Pampalon $R$, Raymond G. A deprivation index for health and welfare planning in Quebec. Chronic Dis Can. 2000;21(3):104-13.

14. Mclntyre D, Muirhead D, Gilson L. Geographic patterns of deprivation in South Africa: informing health equity analyses and public resource allocation strategies. Health Policy Plan. 2002;17(suppl 1):30-9.

15. Wong TW, Wong SL, Yu TS, Liu TS, Lloyd OL. Socioeconomic correlates of infant mortality in Hong Kong. Scand J Soc Med. 1998;26(4):281-8.

16. Al-Baghli NA, Al-Ghamdi AJ, Al-Turki KA, El-Zubaier AG, Al-Mostafa BA, AlBaghli FA, Al-Ameer MM. Awareness of cardiovascular disease in eastern Saudi Arabia. J Family and Community Med. 2010;17(1):15-21.

17. Shah NM, Shah MA, Radovanovic Z. Social class and morbidity differences among Kuwaiti children. J Health Popul Dev Ctries. 1999;2(1):58-69.

18. WHO. Country cooperation strategy for WHO and Saudi Arabia 2006-2011. Cairo: World Health Organisation. p. 2011.

19. CDSI. Population and housing census 1425H [2004]. Central Department of Statistics and Information: Riyadh; 2004

20. Engineering Consultant Group. https://www.farsigeotech.com/. Accessed 12 Aug 2013.

21. Fabrigar LR, Wegener DT. Exploratory factor analysis. USA: OUP; 2012.

22. Kaiser HF, Rice J. Little jiffy, mark IV. Educ Psychol Meas. 1974;34(1):111-7.

23. Bartlett MS: Tests of significance in factor analysis. Br J Psychology 1950, Statistical Section 3:77-85.

24. Hamilton LC. Statistics with STATA: version 12. Boston: Cengage Learning; 2012

25. StataCorp: Stata: Release 12. Statistical Software. In. TX: College Station; 2011

26. Geiser C. Data analysis with Mplus. New York: Guilford publications; 2012.

27. Wang J, Wang X. Structural equation modeling: applications using Mplus. Beijing: Wiley, Higher Education Press; 2012.

28. Muthen LK, Muthen BO. Mplus: statistical analysis with latent variables. A user's guide 7th Edition. In., Seventh Edition EDN Los Angeles, CA; 2012.

29. Nylund KL, Asparouhov T, Muthén BO. Deciding on the number of classes in latent class analysis and growth mixture modelling: a Monte Carlo simulation study. Struct Equ Model. 2007;14(4):535-69.

30. IG AG, Hussain II, MS AG, El-Sheemy MA. The incidence rate of corpus uteri cancer among females in Saudi Arabia: an observational descriptive epidemiological analysis of data from Saudi Cancer registry 2001-2008. Int J Women's Health. 2014;6:141-7. 
31. AIGhamdi IG, Hussain II, AlGhamdi MS, El-Sheemy MA. The incidence rate of prostate cancer in Saudi Arabia: an observational descriptive epidemiological analysis of data from the Saudi Cancer registry 2001-2008. Hematol Oncol Stem Cell Ther. 2014;7(1):18-26.

32. Shaw M, Galobardes B, Lawlor DA, Lynch J, Wheeler B, Smith GD. The handbook of inequality and socioeconomic position. Bristol: Policy Press; 2007.

33. Kishnan V: Constructing an area-based socioeconomic status index: A principal components analysis approach. In: Early Childhood Intervention Australia. Canberra, Australia; 2010.

34. Sekhar CC, Indrayan A, Gupta SM. Development of an index of need for health resources for Indian states using factor analysis. Int J Epidemiol. 1991; 20(1):246-50.

35. Antony GM, Visweswara Rao K. A composite index to explain variations in poverty, health, nutritional status and standard of living: use of multivariate statistical methods. Public Health. 2007;121(8):578-87.

36. Fukuda Y, Nakamura K, Takano T. Higher mortality in areas of lower socioeconomic position measured by a single index of deprivation in Japan. Public Health. 2007;121(3):163-73.

37. Hightower WL. Development of an index of health utilizing factor analysis. Med Care. 1978;16(3):245-55.

38. The Custodian of The Two Holy Mosques' Overseas Scholarship Program. https:/www.moe.gov.sa/en/HigherEducation/ExternalEducation/Pages/ TheCustodianofTheTwoHolyMosquesOverseasScholarshipProgram.aspx. Accessed 25 Jan 2017.

39. Schuurman N, Bell N, Dunn JR, Oliver L. Deprivation indices, population health and geography: an evaluation of the spatial effectiveness of indices at multiple scales. J Urban Health. 2007;84(4):591-603.

\section{Ready to submit your research? Choose BMC and benefit from:}

- fast, convenient online submission

- thorough peer review by experienced researchers in your field

- rapid publication on acceptance

- support for research data, including large and complex data types

- gold Open Access which fosters wider collaboration and increased citations

- maximum visibility for your research: over $100 \mathrm{M}$ website views per year 